\title{
Nanoquasicrystalline Phase in Mechanically Alloyed and Heat-Treated $\mathrm{Al}_{73} \mathrm{Cu}_{11} \mathrm{Cr}_{16}$
}

\author{
T.A. Sviridova ${ }^{a, *}$, A.P. Shevchukov ${ }^{a}$, E.V. Shelekhov ${ }^{a}$, D.L. Diakonov ${ }^{b}$,

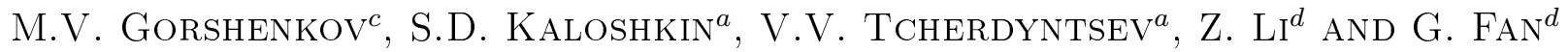 \\ ${ }^{a}$ Center for Composite Materials, National University of Science and Technology "MISIS", Moscow 119049, Russia \\ ${ }^{b}$ Bardin Central Research Institute for the Iron and Steel Industry, Moscow 105005, Russia \\ 'Int. School of Microscopy, National University of Science and Technology "MISIS", Moscow 119049, Russia \\ ${ }^{d}$ State Key Laboratory of Metal Matrix Composites, Shanghai Jiao Tong University, Shanghai 200240, China
}

X-ray diffraction analysis, scanning and transmission electron microscopy, thermal analysis and measurement of chemical composition were implemented to determine structure, thermal stability and chemical composition of the decagonal quasicrystal in $\mathrm{Al}_{73} \mathrm{Cu}_{11} \mathrm{Cr}_{16}$ alloy produced by long-term mechanical alloying of elemental powders followed by annealing at $700{ }^{\circ} \mathrm{C}$. According to the TEM investigation such a technique permits to produce a single-phase nanostructural quasicrystal with grain size about $60 \mathrm{~nm}$. Differential thermal analysis revealed that the decagonal phase does not exist above $923^{\circ} \mathrm{C}$ and undergoes incongruent two-stage melting coming to the end at $1100^{\circ} \mathrm{C}$.

DOI: $10.12693 /$ APhysPolA.126.599

PACS: 61.44.Br, 64.70.kd, 61.05.cp, 61.05.J-

\section{Introduction}

Owing to their very unusual electronic and transport features and promising mechanical properties such as hardness, adhesion and friction, quasicrystals have a very good perspective in various applications as protective coatings or fillers of composite materials. Since nanostructural materials are known to have improved mechanical properties, nanocrystalline quasicrystals give us an additional opportunity to produce materials with useful characteristics.

Nanoquasicrystalline phases could be fabricated by various methods. Thus the melt spinning was used to obtain a composite material in $\mathrm{Al}-\mathrm{Fe}-\mathrm{Cr}-\mathrm{Z}$ alloys $(\mathrm{Z}=\mathrm{Ti}$, $\mathrm{V}, \mathrm{Nb}, \mathrm{Ta})$ with rounded nanoquasicrystalline particles $(80 \div 250 \mathrm{~nm})$ embedded into Al-matrix [1]. The similar composite material with quasicrystalline and intermetallic nanoparticles $(200 \div 1000 \mathrm{~nm})$ can be produced by gas atomization [2]. The mechanical alloying is known to be a non-expensive method to attain nanostructural state and followed by annealing it can be used to synthesize complex intermetallic compounds including quasicrystals. For example, nanostructural icosahedral quasicrystal was produced in $\mathrm{Al}_{70} \mathrm{Cu}_{20} \mathrm{Fe}_{10}$ as a result of mechanical alloying of elemental blend followed by annealing at $600{ }^{\circ} \mathrm{C}$ for $4 \mathrm{~h} \mathrm{[3]}$. In our previous works a similar procedure was applied to obtain decagonal quasicrystals in $\mathrm{Al}-\mathrm{Cu}-\mathrm{Cr}$ system $[4,5]$.

It is worth noting that up to now there is no complete phase diagram of the $\mathrm{Al}-\mathrm{Cu}-\mathrm{Cr}$ system and it is

*corresponding author; e-mail: sviridova@misis.ru not yet clear how many various quasicrystalline phases can be created in the system depending on the producing methods. Shortly, at least two different decagonal quasicrystals with dissimilar periodicities along tenfold direction were found in $\mathrm{Al}-\mathrm{Cu}-\mathrm{Cr}$ system. In [6] $\mathrm{D}_{3}$ and $\mathrm{D}_{9}$ phases (in terms [7]) with translation length of 1.24 and $1.24 \times 3=3.72 \mathrm{~nm}$ respectively were found by transmission electron microscopy (TEM) in rapidly solidified $\mathrm{Al}_{67} \mathrm{Cu}_{18} \mathrm{Cr}_{25}$. Decagonal $\mathrm{D}_{9}-\mathrm{Al}_{72} \mathrm{Cu}_{12} \mathrm{Cr}_{16}$ phase was found in as-cast alloys $\mathrm{Al}_{70} \mathrm{Cu}_{10} \mathrm{Cr}_{20}$ [8] and $\mathrm{Al}_{71} \mathrm{Cu}_{12} \mathrm{Cr}_{17}$ [9] coexisting with $\mathrm{Al}_{17} \mathrm{Cr}_{9}$ and $\mathrm{CuAl}_{2}$ phases while long-term annealing revealed that $\mathrm{D}_{9}$ phase is stable in extremely narrow temperature range around $1000{ }^{\circ} \mathrm{C}[10]$. And at least two different decagonal quasicrystals $-\mathrm{D}_{3}-\mathrm{Al}_{71.4} \mathrm{Cu}_{19.2} \mathrm{Cr}_{9.4}$ and $d$-phase with unknown periodicity $\mathrm{Al}_{73} \mathrm{Cu}_{11} \mathrm{Cr}_{16}$ - were obtained by mechanical alloying (MA) and subsequent annealing in $[4,5]$.

The main goal of this work is to characterize quasicrystalline phase in $\mathrm{Al}-\mathrm{Cu}-\mathrm{Cr}$ system obtained earlier by combination of mechanical alloying and annealing [4].

\section{Materials and methods}

The mixture of elemental powders (purity 98.0\%, powder size $\approx 250 \mu \mathrm{m}), \mathrm{Cu}(99.5 \%, \approx 30 \div 50 \mu \mathrm{m})$ and Cr $(98.5 \%, \approx 30 \div 50 \mu \mathrm{m})$ with nominal composition of $\mathrm{Al}_{73} \mathrm{Cu}_{11} \mathrm{Cr}_{16}$ was mechanically alloyed in $\mathrm{Ar}$ atmosphere using the AGO-2M planetary ball mill at $620 \mathrm{rpm}$ for 14 hours. The powder-to-ball ratio was 1:10, $200 \mathrm{~g}$ of balls were charged in a vial with filling ratio $35 \div 40 \%$. The $0.2 \mathrm{ml}$ of ethanol served as a process control agent preventing powder adhesion on work surfaces.

As-milled powder was annealed for $1 \mathrm{~h}$ at the $700^{\circ} \mathrm{C}$ in a pipe furnace under Ar atmosphere and then air-cooled. 
Differential scanning calorimetry (DSC) were carried out using simultaneous thermal analyzer NETZSCH STA 449 F3 Jupiter with heating and cooling rates $10 \mathrm{~K} / \mathrm{min}$.

Phase composition was determined by X-ray diffraction (XRD) analysis by means of $\mathrm{Co} K_{\alpha}$ radiation. Chemical composition of annealed powder was measured by both the inductively coupled plasma atomic emission spectroscopy (ICP-AES) and energy-dispersive spectroscopy (EDS).

The powder microstructure was examined using scanning electron microscope JEOL JSM6610LV with energydispersive spectroscopy (EDS) equipment. The quasicrystalline phase was characterized by transmission electron microscopy (TEM) using the JEM-200CX microscope.

\section{Results and discussion}

The combination of mechanical alloying with milling time $14 \mathrm{~h}$ and subsequent annealing at $700^{\circ} \mathrm{C}$ for $1 \mathrm{~h}$ was used to synthesize a ternary intermetallic compound $\mathrm{Al}_{73} \mathrm{Cu}_{11} \mathrm{Cr}_{16}$ from an elemental blend. The annealing mode was selected based on previous experiments [4]. Fig. 1 shows microstructures of as-milled (a) and asannealed (b) samples. Figure 1a demonstrates clearly visible white submicron $\mathrm{Cr}$-particles amidst a gray "matrix" which, judging by EDS analysis, contains all closely intermixed alloy constituents. The relatively slow dissolution of $\mathrm{Cr}$ is due to its higher hardness compared to other plastic alloy components. XRD analysis (Fig. 2a) shows that as-milled sample contains three crystalline phases - $\mathrm{Al}, \mathrm{Cr}$ and $\mathrm{CuAl}_{2}$ intermetallic.

As follows from Fig. 1b, the as-annealed sample consists of only one phase. Since the corresponding XRD pattern (Fig. 2b) resembles the one obtained from decagonal quasicrystal with a periodicity along 10-fold axis $1.26 \mathrm{~nm}$ [5] we can assume that the as-annealed sample contains a similar quasicrystalline phase ( $d$-phase).

Several methods were used to characterize the singlephase as-annealed sample. TEM was applied to measure the grain size and periodicity along 10-fold axis. Figure 3 a shows bright-field image of the nanostructural powder with average grain size about $60 \mathrm{~nm}$. Two electron diffraction patterns (Fig. 3b,c) clearly indicate that the as-annealed sample of $\mathrm{Al}_{73} \mathrm{Cu}_{11} \mathrm{Cr}_{16}$ alloy is a decagonal quasicrystal. Figure $3 \mathrm{~b}$ predominantly measured from a single grain shows 10-fold symmetry whereas the other diffraction pattern (Fig. 3c) is a typical one along 2fold axis (2D). The periodicity along 10-fold axis measured from Fig. 3c and refined by indexing the corresponding XRD pattern (Fig. 2b) is $1.264 \mathrm{~nm}$. But it should be noted that electron diffraction pattern of $\mathrm{D}_{9-}$ quasicrystal differs from $\mathrm{D}_{3}$ phase only by additional rows of weak spots between strong reflections rows [8]. Since the diffraction pattern (Fig. 3c) contains redundant reflections coming from adjacent grains, it is difficult, if not impossible, to distinguish in our case these two decagonal quasicrystals.
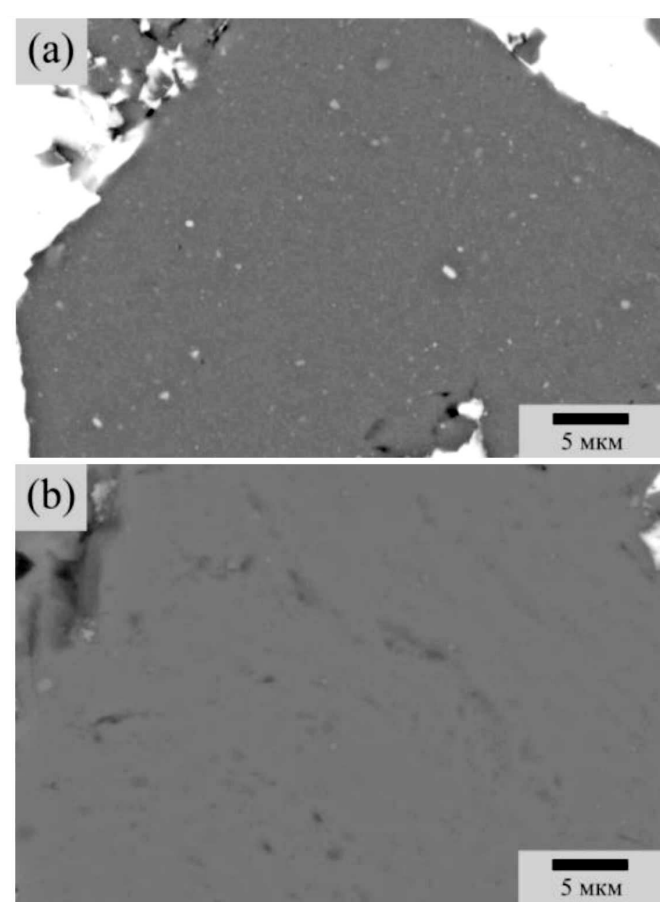

Fig. 1. Microstructure of as-milled (a) and as-annealed (b) samples. The white periphery of the particle is tin, which served as a binder during the sample preparation.

The composition of as-annealed quasicrystalline phase was found to be $\mathrm{Al}_{71.5} \mathrm{Cu}_{11.5} \mathrm{Cr}_{16.5} \mathrm{Fe}_{0.5}$ (EDS). As-milled powder had quite similar composition: $\mathrm{Al}_{72.7} \mathrm{Cu}_{11.1} \mathrm{Cr}_{15.7} \mathrm{Fe}_{0.5}$ (by ICP-AES) and $\mathrm{Al}_{72.2} \mathrm{Cu}_{11.1} \mathrm{Cr}_{16.2} \mathrm{Fe}_{0.5}$ (by EDS). The Fe-doping is due to wear of milling tools.

Figure 4 shows three DSC curves of the $\mathrm{Al}_{73} \mathrm{Cu}_{11} \mathrm{Cr}_{16}$ alloy. First two curves (Fig. 4a,b) are taken on the first and second heating of as-milled powder, respectively, the last one (Fig. 4c) is obtained on heating of as-annealed powder $\left(700^{\circ} \mathrm{C}, 1 \mathrm{~h}\right)$. It should be noted that the first heating gives rise to complete melting of the sample. Figure $2 \mathrm{c}$ demonstrates an XRD pattern of as-milled powder after the second heating in calorimeter, which slightly differs from as-annealed sample.

As it was determined earlier [4], the first heating of asmilled powder (Fig. 4a) results in the two-stage formation of the $d$-phase. First step of the transformation takes place in the temperature range of $250 \div 450{ }^{\circ} \mathrm{C}$ and mainly relates to $\mathrm{CuAl}_{2}$ phase formation with minor dissolution of $\mathrm{Cr}$. The second stage occurs at $520 \div 640^{\circ} \mathrm{C}$ where $\mathrm{Cr}$ dissolution becomes appreciable and the single product of this process is a decagonal quasicrystal.

Since the exothermic effect at $795^{\circ} \mathrm{C}$ appears only in samples that were not melted (Fig. $4 \mathrm{a}$ and c), this effect is likely the release of excess energy of grain boundaries in nanocrystalline as-milled and as-annealed samples induced by grains growth. The volume fraction of highangle grain boundaries can be estimated as $3 d / D$, where $d \approx 1 \mathrm{~nm}$ is a grain boundary thickness and $D$ is a grain 

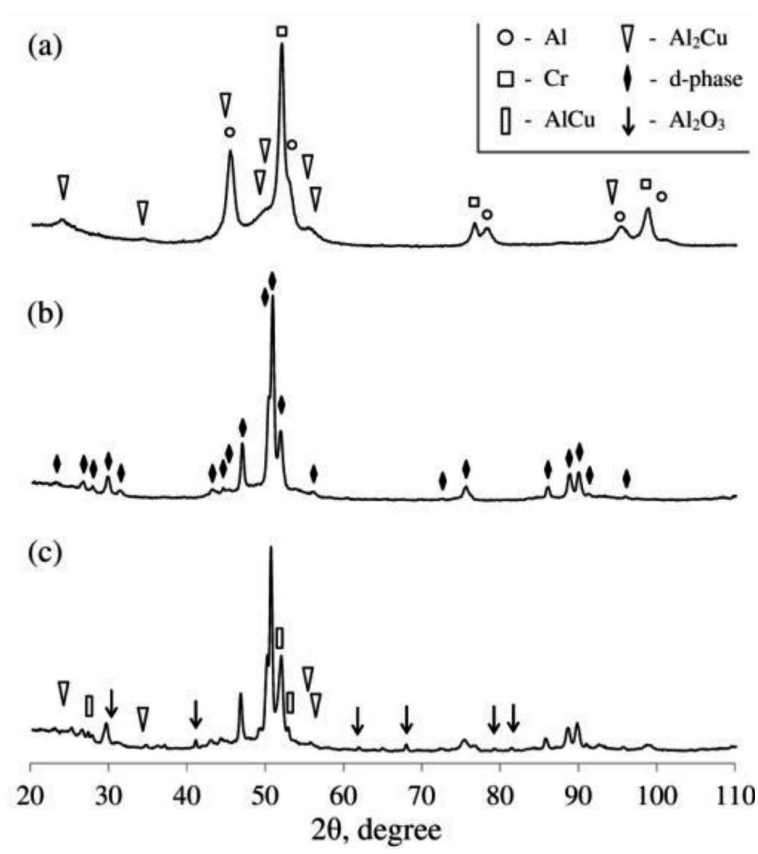

Fig. 2. XRD patterns of as-milled (a) and asannealed (b) samples and as-annealed powder on repeated heating in calorimeter up to $1250^{\circ} \mathrm{C}$ (c).
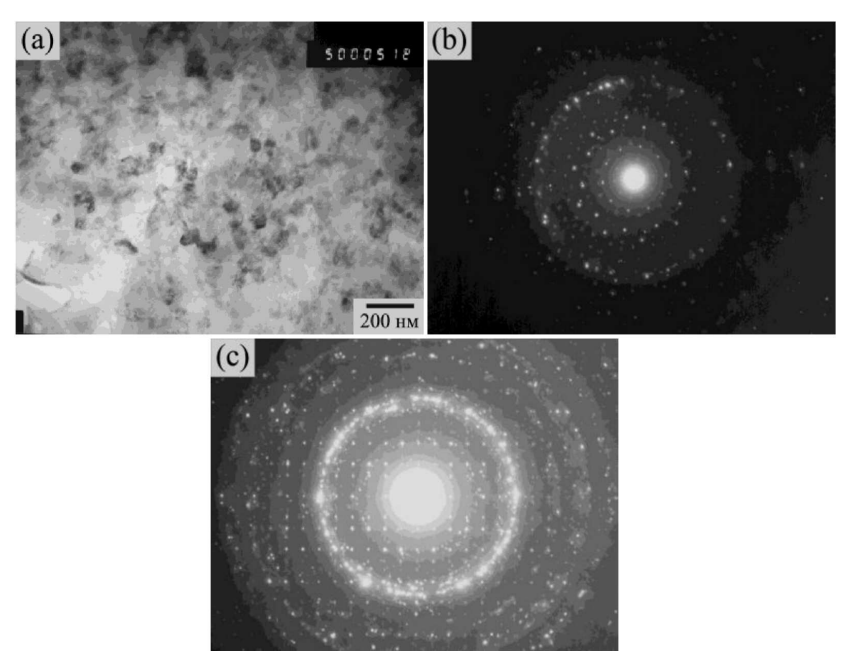

Fig. 3. Bright-field image (a) and diffraction patterns along 10 -fold (b) and 2-fold axes obtained by TEM from the as-annealed sample of $\mathrm{Al}_{73} \mathrm{Cu}_{11} \mathrm{Cr}_{16}$ alloy (c).

size. Assuming that atomic structure inside grain boundary is close to that in the melt, i.e. its excess entropy is $R$ and excess energy is $R T$ ( $R$ is gas constant, $T$ is a transformation temperature), the energy of grain boundaries can be evaluated as

$$
U=R T 3 d / D \text {. }
$$

Using the experimentally measured by TEM grain size $D=60 \mathrm{~nm}$, this estimation gives $U \approx 450 \mathrm{~J} / \mathrm{mol}$ (for non-eqiulateral grains it would be greater), whereas experimentally measured effect is about $750 \mathrm{~J} / \mathrm{mol}$.

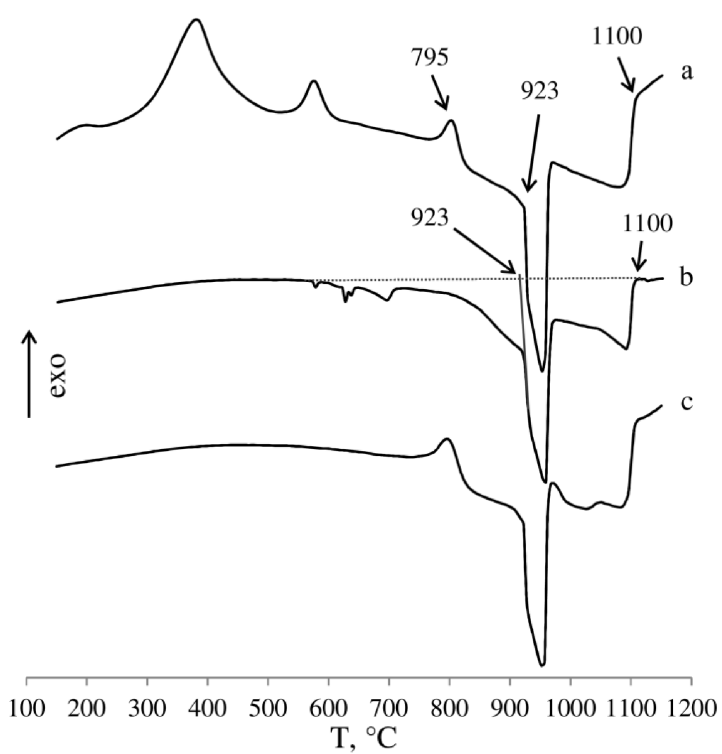

Fig. 4. DSC curves on first (a) and second (b) heating of as-milled sample and (c) heating of as-annealed powder.

All other transformations above $650{ }^{\circ} \mathrm{C}$ relates to the incongruent melting of the $d$-phase coming to the end at $1100^{\circ} \mathrm{C}$. The major endothermic effect at $923^{\circ} \mathrm{C}$ corresponds to the first step of melting which, judging by the isothermal cross sections of $\mathrm{Al}-\mathrm{Cu}-\mathrm{Cr}$ phase diagram [10], should occur through several stages:

$$
d \text {-phase } \rightarrow L+\zeta \rightarrow L+\gamma_{2}-\mathrm{Al}_{9} \mathrm{Cr}_{4} \rightarrow L,
$$

where $L$ is a liquid phase and $\zeta$ is a ternary hexagonal phase with a wide homogeneity region about $\mathrm{Al}_{72} \mathrm{Cu}_{13} \mathrm{Cr}_{15}$ [10].

The curve in Fig. 4b predictably lacks for exothermic peaks corresponding to $d$-phase formation but demonstrates three weak endothermic effects below $700^{\circ} \mathrm{C}$. All of them are very close to non-variant temperatures in $\mathrm{Al}-\mathrm{Cu}$ or $\mathrm{Al}-\mathrm{Cr}$ systems. It means that cooling rate in calorimeter is not slow enough to reach equilibrium condition since the termination of a peritectic reaction needs retarding this process solid-state diffusion. As a result the corresponding XRD pattern (Fig. 2c) besides the $d-$ phase reflections contains the several weak peaks of $\mathrm{CuAl}$ and $\mathrm{CuAl}_{2}$ phases as well as $\alpha-\mathrm{Al}_{2} \mathrm{O}_{3}$ phase.

\section{Conclusion}

Long-term mechanical alloying of elemental powders with subsequent annealing at $700{ }^{\circ} \mathrm{C}$ for 1 hour was used to produce a single-phase nanostructural decagonal quasicrystal in $\mathrm{Al}_{73} \mathrm{Cu}_{11} \mathrm{Cr}_{16}$ alloy. The as-annealed quasicrystalline sample was characterized by X-ray diffraction analysis, scanning and transmission electron microscopy and thermal analysis. Its exact chemical composition was found to be $\mathrm{Al}_{71.5} \mathrm{Cu}_{11.5} \mathrm{Cr}_{16.5} \mathrm{Fe}_{0.5}$ and it is stable up to $923{ }^{\circ} \mathrm{C}$. Above this temperature decagonal quasicrystal undergoes incongruent two-stage melting 
coming to the end at $1100{ }^{\circ} \mathrm{C}$. As follows from transmission electron microscopy, the quasicrystal periodicity along 10-fold axis most likely is $1.26 \mathrm{~nm}$.

\section{Acknowledgments}

This work was supported by the Federal Program "Scientific and scientific-pedagogical personnel of innovative Russia" (State Contract 14.740.11.1012) and by the Russian Foundation for Basic Research (Project number 1208-91162).

\section{References}

[1] M. Galano, F. Audebert, I.C. Stone, B. Cantor, Acta Mater. 57, 5107 (2009).

[2] F. Audebert, M. Galano, C. Triveno Rios, H. Kasama, M. Peres, C. Kiminami, W.J. Botta, C. Bolfarini, J. Alloys Comp. 577, 650 (2013).

[3] V. Srinivas, P. Barua, T.B. Ghosh, B.S. Murty, J. Non-Cryst. Solids 334\&335, 540 (2004).
[4] A.P. Shevchukov, T.A. Sviridova, S.D. Kaloshkin, V.V. Tcherdyntsev, M.V. Gorshenkov, M.N. Churyukanova, D. Zhang, Z. Li, J. Alloys Comp. 586S, S391 (2013).

[5] T.A. Sviridova, A.P. Shevchukov, E.V. Shelekhov, D.L. Diakonov, V.V. Tcherdyntsev, S.D. Kaloshkin, J. Alloys Comp. 509S, S299 (2011).

[6] J.S. Wu, X.L. Ma, K.H. Kuo, Philos. Mag. Lett. 73, 163 (1996).

[7] B. Grushko, T.Ya. Velikanova, J. Alloys Comp. 367, 58 (2004).

[8] T. Okabe, J.-I. Furihata, K. Morishita, H. Fujimori, Philos. Mag. Lett. 66, 259 (1992).

[9] J.-I. Furihata, T. Okabe, J. Electr. Microsc. 48, 761 (1999).

[10] B. Grushko, E. Kowalska-Strzęciwilk, B. Przepiórzyński, M. Surowiec, J. Alloys Comp. 417, 121 (2006). 